\title{
Desempenho e atividade de amilase em tilápias-do-nilo submetidas a diferentes temperaturas
}

\author{
Guilherme de Souza Moura ${ }^{(1)}$, Maria Goreti Almeida Oliveira(2), Eduardo Teixeira Arruda Lanna ${ }^{(1)}$, \\ Alaor Maciel Júnior ${ }^{(3)}$ e Cláudia Maria Reis Raposo Maciel(4)
}

\begin{abstract}
(1)Universidade Federal de Viçosa (UFV), Dep. de Zootecnia, Av. P.H. Rolfs, s/no, Campus Universitário, CEP 36570-000 Viçosa, MG. E-mail: mouraguilherme@yahoo.com.br, elanna@ufv.br (2)UFV, Instituto de Biotecnologia Aplicada à Agropecuária. E-mail: malmeida@ufv.br (3)Universidade Estadual do Sudoeste da Bahia (UESB), Dep. de Tecnologia Rural e Animal, Praça da Primavera, no 40, Bairro Primavera, CEP 45700-000 Itapetinga, BA. E-mail: alaor@uesb.br (4)UESB, Dep. de Estudos Básicos e Instrumentais. E-mail: crmaciel@uesb.br
\end{abstract}

\begin{abstract}
Resumo - O objetivo deste trabalho foi avaliar o desempenho e a atividade de amilase em quimo de tilápias-do-nilo macho, linhagem tailandesa, submetidas a quatro diferentes temperaturas. O experimento foi conduzido em delineamento inteiramente casualizado, com quatro tratamentos $\left(20,24,28\right.$ e $\left.32^{\circ} \mathrm{C}\right)$, seis repetições e dez peixes por unidade experimental. A dieta utilizada foi igual para todos os tratamentos. Aos 55 dias do experimento, o consumo de ração aparente, ganho de peso, conversão alimentar aparente, atividade de amilase e atividade específica da amilase foram avaliados. O consumo de ração aparente e o ganho de peso aumentaram linearmente com o aumento da temperatura. Na conversão alimentar aparente, foi observado efeito quadrático em função da temperatura com melhora na conversão de 1,79 a 1,00 com o aumento da temperatura até $29,15^{\circ} \mathrm{C}$. Observou-se efeito linear na atividade da amilase e na atividade específica da amilase em função da temperatura, com maior atividade de amilase e menor atividade específica de amilase a $32^{\circ} \mathrm{C}$. A temperatura da água influencia o desempenho e a atividade da amilase em tilápias-do-nilo.
\end{abstract}

Termos para indexação: Oreochromis niloticus, enzimas, fisiologia de peixes, piscicultura.

\section{Performance and amylase activity in Nile tilapia submitted to different temperatures}

\begin{abstract}
The objective of this work was to evaluate the performance and amylase activity in chime of Nile tilapia male, Thai line, submitted to four different temperatures. The experimental design was completely randomized with four treatments $\left(20,24,28\right.$ and $\left.32^{\circ} \mathrm{C}\right)$, six replicates and ten fishes per experimental unit. The diet was the same for all treatments. At 55 days of experiment, apparent feed intake, weight gain, apparent feed conversion, amylase activity and specific amylase activity were evaluated. The apparent feed intake and weight gain increased linearly with temperature increase. For apparent feed conversion, quadratic effect was observed as a function of temperature, showing a conversion improvement of 1.79 to 1.00 with the increase of the temperature until $29,15^{\circ} \mathrm{C}$. Linear effect in amylase activity and specific amylase activity was observed as a result of temperature, comprising high amylase activity and low specific amylase activity at $32^{\circ} \mathrm{C}$. Water temperature influences the performance and amylase activity in Nile tilapia.
\end{abstract}

Index terms: Oreochromis niloticus, enzymes, fish physiology, pisciculture.

\section{Introdução}

Muitos alimentos vêm sendo testados com a finalidade de melhorar o bem estar e o desempenho dos peixes. No entanto, informações a respeito da influência ambiental e dos processos fisiológicos da digestão são escassas, não permitindo o avanço do conhecimento para otimizar, nutricionalmente, as dietas comerciais. Pelo fato de os peixes serem animais ectotérmicos, a temperatura do meio onde vivem influencia o seu metabolismo fisiológico, afetando os processos de digestão e, conseqüentemente, o desempenho.

Temperaturas acima de $32^{\circ} \mathrm{C}$ e abaixo de $27^{\circ} \mathrm{C}$ reduzem o apetite e o crescimento de tilápias, e abaixo de $18^{\circ} \mathrm{C}$ suprimem o sistema imunológico (Kubitza, 2000). Em juvenis de tainhas submetidas a várias temperaturas, houve melhora na taxa de crescimento e conversão alimentar, quando esses peixes foram submetidos a $30^{\circ} \mathrm{C}$ (Okamoto et al., 2006). De maneira geral, cada espécie de peixe possui uma faixa de temperatura na qual eles 
expressam maior potencial de crescimento (Piedras et al., 2004), o que pode estar diretamente relacionado com a atividade enzimática dos processos digestórios.

A amilase é uma das enzimas digestivas, de origem pancreática, que age no intestino delgado sobre os polissacarídeos presentes no quimo. Embora os carboidratos constituam um dos três principais componentes das dietas de animais utilizados como fontes de energia para crescimento, as funções biológicas e a metabolização desse nutriente em peixes ainda não estão totalmente entendidas (Peragón et al., 1994).

A fim de avaliar a digestibilidade de novos alimentos com maior precisão, Glass et al. (1989) recomendam o conhecimento da quantidade e especificidade de cada enzima presente no sistema digestivo e as condições em que ocorre a hidrólise. A estreita relação entre as enzimas presentes no trato digestivo dos peixes e a utilização dos nutrientes da dieta tem sido demonstrada. Segundo Shiau \& Chuang (1995), peixes onívoros são relativamente eficientes na utilização dos carboidratos da dieta e produzem as enzimas digestivas associadas à degradação e metabolismo de pós-absorção dos açúcares.

Sabapathy \& Teo (1993), ao analisar a distribuição e atividade de enzimas digestivas no tubo digestivo de Siganus canaliculatus (onívoro) e de Lates calcarifer (carnívoro), relataram a capacidade de digestão de carboidratos dessas espécies devido à presença de amilase no tubo digestivo. Estudos realizados em espécies juvenis de pacu Piaractus mesopotamicus (Moraes \& Bidinotto, 2000), tambaqui Colossoma macropomum (Correa, 2002) e em híbrido tambacu C.macropomum x P. mesopotamicus (Correa et al., 1998) mostraram a indução da atividade da amilase nas diferentes regiões do trato digestivo dos peixes com a utilização de diferentes níveis de carboidratos na ração. Em larvas de "sea bass" (Dicentrarchus labrax), Cahu \& Zambonino-Infante (1994) verificaram aumento da atividade da amilase, quando esses animais receberam dietas com $12 \%$ de amido, em relação às larvas que receberam alimento vivo.

Segundo Seixas Filho et al. (1999), a diferença observada na atividade específica da amilase pancreática da piracanjuba (Brycon orbignyanus) e do piau (Leporinus friderici) pode ter ocorrido em virtude da morfometria e do complexo arranjo de pregas da mucosa dos intestinos médio e posterior desses peixes. Além disso, os autores verificaram que a atividade da amilase do surubim (Pseudoplatystoma coruscans) indicou a possibilidade de uso de ração que contém carboidratos na dieta dessas espécies.

As informações sobre o padrão de desenvolvimento de enzimas digestivas pancreáticas, suas secreções no duodeno e atividades nos conteúdos intestinais são importantes para a projeção e implementação de estratégias nutricionais e dietéticas para melhorar a utilização de nutrientes pelos animais (Jin et al., 1998). Porém, essas informações não são suficientes para promover melhor desempenho de peixes, visto que a temperatura promove mudanças na fisiologia da digestão e na velocidade das reações metabólicas (Purchase \& Brown, 2001). Portanto, é necessário um conhecimento maior sobre a relação existente entre atividade enzimática e o ambiente.

O objetivo deste trabalho foi avaliar o desempenho e a atividade de amilase de tilápia-do-nilo submetida a quatro temperaturas.

\section{Material e Métodos}

O experimento foi conduzido no Laboratório de Nutrição de Peixes do Departamento de Zootecnia da Universidade Federal de Viçosa, no período de 27/7/2005 a 20/9/2005.

O sistema de recirculação foi formado por quatro reservatórios de polietileno, com capacidade de $500 \mathrm{~L}$ de água. $\mathrm{O}$ abastecimento dos reservatório foi feito por gravidade, e o nível da água foi controlado individualmente. Esses reservatórios abasteceram, por bombeamento contínuo, quatro fileiras de seis aquários de $100 \mathrm{~L}$ cada, que corresponderam às unidades experimentais.

Para manter a temperatura de cada unidade experimental, o controle da vazão foi regulado a fim de compensar as perdas de calor do sistema. $\mathrm{O}$ volume de água que abastecia os aquários retornava aos reservatórios por meio de sifão articulado em cada aquário, que conduzia a água efluente para tubulações de retorno. Essas, por sua vez, devolviam a água para os reservatórios, fechando, assim, o circuito.

Foram utilizados filtros, acoplados às motobombas, visando evitar a recirculação de partículas em suspensão, remover a amônia residual e evitar o desgaste das unidades formadoras do sistema de recirculação.

Em cada reservatório, foi instalada uma resistência elétrica tubular blindada de $3.000 \mathrm{~W}$ para o aquecimento da água. Cada resistência foi acionada por um 
controlador digital de temperatura (termostato), com ajuste diferencial de $-0,3^{\circ} \mathrm{C}$, programado para as respectivas temperaturas testadas.

A cada aquário, foi fornecida aeração suplementar por meio de um aerador central, evitando diferenças nos níveis de oxigênio dissolvido na água. Dessa forma, foi possível compensar as perdas de oxigênio devido à temperatura, mantendo-se os níveis próximos à saturação em todos os aquários.

Diariamente, a limpeza dos aquários e dos reservatórios foi feita por sifonagem do fundo, além da troca dos filtros. A temperatura da água foi aferida diariamente, às $18 \mathrm{~h}$, com o auxílio de termômetro digital, e os níveis de oxigênio da água e o pH foram medidos semanalmente com o auxílio de peagômetro e oxímetro digitais portáteis, respectivamente.

Foram utilizados 240 alevinos machos de tilápia-donilo, da linhagem Tailandesa, com peso inicial de 0,835 $\pm 0,004$ g, distribuídos em 24 aquários, com dez indivíduos por unidade experimental. Depois da distribuição, os termostatos foram ajustados para que a água, a partir de $24^{\circ} \mathrm{C}$ (temperatura de origem), atingisse as respectivas temperaturas nas quais os animais seriam mantidos, numa taxa de aumento de $1^{\circ} \mathrm{C}$ a cada seis horas. Assim, após 48 horas, todas as temperaturas-teste estavam estabilizadas. O início do experimento foi considerado a partir desse momento.

$\mathrm{O}$ delineamento experimental foi inteiramente casualizado, com quatro tratamentos (temperaturas-tesse de $20,24,28$ e $32^{\circ} \mathrm{C}$ ), com seis repetições e dez peixes por unidade experimental.

Os peixes receberam a mesma dieta à vontade (Tabela 1), fornecida quatro vezes ao dia $(8 \mathrm{~h} 30,11 \mathrm{~h} 30$, $14 \mathrm{~h} 30$ e 17h30), evitando-se as sobras.

Aos 55 dias de experimento, foram avaliados o consumo de ração aparente $(\mathrm{g})$, ganho de peso $(\mathrm{g})$, conversão alimentar aparente $\left(\mathrm{g} \mathrm{g}^{-1}\right)$, atividade de amilase (UA) e atividade específica de amilase $\left(\mathrm{UA} \mathrm{mg}^{-1}\right)$. $\mathrm{O}$ consumo de ração aparente foi calculado pelo peso inicial da dieta menos o peso da sobra dessa mesma dieta, ao final do experimento. O cálculo do ganho de peso foi obtido pela média do peso final menos a média do peso inicial dos peixes. A conversão alimentar aparente foi calculada dividindo-se o consumo de ração pelo ganho de peso das tilápias.

$\mathrm{Na}$ análise da atividade da amilase e atividade específica de amilase, as tilápias foram retiradas e, imediatamente, colocadas em banho de gelo para morte e paralisação das atividades enzimáticas, num total de seis amostras de cada tratamento. Os peixes sofreram incisão longitudinal ventral, com posterior isolamento da porção cranial do esôfago e da porção caudal do reto, por meio de ligaduras duplas, para evitar o extravasamento do quimo das regiões a serem estudadas. Após o isolamento, o intestino médio e o posterior foram retirados e acondicionados em frascos de polietileno. Esse material foi imediatamente congelado e armazenado em freezer a $-8^{\circ} \mathrm{C}$.

As análises de atividade da amilase foram realizadas no Laboratório de Enzimologia, Bioquímica de Proteínas e Peptídeos do Instituto de Biotecnologia Aplicada à

Tabela 1. Composição porcentual e química da dieta experimental (matéria natural).

\begin{tabular}{|c|c|}
\hline Composição & Quantidade (\%) \\
\hline Farelo de soja & 51,193 \\
\hline Milho & 32,709 \\
\hline Glúten 60 & 10,104 \\
\hline Óleo de soja & 1,899 \\
\hline Fosfato bicálcico & 3,025 \\
\hline Premix vitamínico ${ }^{(1)}$ & 0,400 \\
\hline Premix mineral $^{(1)}$ & 0,100 \\
\hline Vitamina C & 0,050 \\
\hline Sal & 0,500 \\
\hline Antioxidante (BHT) & 0,020 \\
\hline Total & 100,000 \\
\hline \multicolumn{2}{|c|}{ Composição calculada $^{(2)}$} \\
\hline Proteína bruta (\%) & 32,00 \\
\hline Proteína digestível $(\%)^{(3)}$ & 29,09 \\
\hline Energia digestível $\left(\mathrm{kcal} \mathrm{kg}^{-1}\right)^{(3)}$ & 3.000 \\
\hline Extrato etéreo (\%) & 4,17 \\
\hline Ácido linoléico & 2,14 \\
\hline Fibra bruta $(\%)$ & 3,44 \\
\hline Cálcio total $(\%)$ & 0,89 \\
\hline Fósforo disponível (\%) ${ }^{(4)}$ & 0,60 \\
\hline Lisina total $(\%)^{(5)}$ & 1,598 \\
\hline Lisina digestível $(\%)^{(5)}$ & 1,450 \\
\hline Met. + Cist. total $(\%)^{(5)}$ & 1,016 \\
\hline Met. + Cist. digestível $(\%)^{5)}$ & 0,953 \\
\hline Treonina total (\%) & 1,228 \\
\hline Treonina digestível (\%) & 1,102 \\
\hline Triptofano total (\%) & 0,372 \\
\hline Triptofano digestível (\%) & 0,343 \\
\hline
\end{tabular}

${ }^{(1)}$ Suplemento vitamínico e mineral comercial para peixes; níveis de garantia (por kg do produto): vit. A, $1.200 .000 \mathrm{UI}$; vit. B1, $4.800 \mathrm{mg}$; vit. B12, 4,8 mg; vit. B2, $4.800 \mathrm{mg}$; vit. B6, $4.800 \mathrm{mg}$; vit. C, $48 \mathrm{~g}$; vit. D3, $200.000 \quad$ UI; vit. E, $1.200 \mathrm{mg}$; vit. K3, $2.400 \mathrm{mg}$; ác. fólico, $1.200 \mathrm{mg}$; biotina, $48 \mathrm{mg}$; pantotenato de cálcio, $12.000 \mathrm{mg}$; cloreto de colina, $108 \mathrm{~g}$; niacina, $24.000 \mathrm{mg}$; selênio, $100 \mathrm{mg}$; iodo, $100 \mathrm{mg}$; cobalto, $10 \mathrm{mg}$; cobre, $3.000 \mathrm{mg}$; ferro, $50.000 \mathrm{mg}$; manganês, $20.000 \mathrm{mg}$; zinco, $30.000 \mathrm{mg}$; veículo Q.S.P., $1.000 \mathrm{~g}$; antioxidante, $25 \mathrm{~g}$. (2) Valores estimados com base nos coeficientes de digestibilidade dos ingredientes segundo Rostagno et al. (2005). ${ }^{(3)}$ National Research Council (1993). ${ }^{(4)}$ Ribeiro et al. (2006). ${ }^{(5)}$ Furuya et al. (2006). 
Agropecuária (Bioagro) da UFV, no período de 21/9/2005 a 20/1/2006.

Nas análises, utilizaram-se $0,5 \mathrm{~g}$ de cada amostra congelada e $1,5 \mathrm{~mL}$ de tampão (Tris- $\mathrm{HCl} 0,1 \mathrm{M}$ ), para descongelamento e maceração. Em seguida, esse material foi centrifugado a $15.000 \mathrm{rpm}$ por $15 \mathrm{~min} \mathrm{a} 4^{\circ} \mathrm{C}$, e o sobrenadante, utilizado nas determinações da atividade de amilase em duplicata.

A determinação da atividade de amilase baseia-se na hidrólise do amido pela amilase, com liberação de moléculas de glicose e dextrina. Pela adição de iodo, o amido não hidrolisado adquire coloração azul. A atividade da amilase é inversamente proporcional à intensidade de cor azul e calculada pela comparação com um controle de substrato. A atividade foi determinada em espectrofotômetro óptico, em comprimento de onda de $660 \mathrm{~nm}$, utilizando-se o kit de amilase colorimétrica da Bioclin, segundo Caraway (1959). A atividade específica de amilase foi obtida pela divisão do valor da atividade de amilase pelo valor da concentração de proteína da respectiva amostra.

A concentração de proteína da amostra foi medida em espectrofotômetro óptico na absorvância de $280 \mathrm{~nm}$. A presença de ácidos nucléicos causou interferências nas leituras ópticas. Este problema foi solucionado realizando-se uma leitura a $260 \mathrm{~nm}$, pois os ácidos nucléicos absorvem mais fortemente a luz neste comprimento de onda. A razão desses dois valores foi determinada e usada para selecionar um fator correção. A absorvância de $280 \mathrm{~nm}$ foi multiplicada por este fator e, com isso, a concentração de proteína, em $\mathrm{mg} \mathrm{mL}^{-1}$, foi obtida (Warburg \& Christian, 1941).

Os dados foram submetidos à análise de variância e regressão linear com o auxílio do SAEG (Universidade Federal de Viçosa, 2004).

\section{Resultados e Discussão}

O sistema de recirculação foi eficiente em manter a qualidade da água em níveis aceitáveis (Tabela 2) de acordo com Boyd (1982), Piper et al. (1982) e Kubitza (2000).

O consumo de ração aparente pelas tilápias aumentou linearmente $(p<0,01)$ com a elevação da temperatura (Tabela 3), mostrando que este fator pode interferir no desempenho. Segundo Kubitza (2000), quando a temperatura da água diminui, as tilápias reduzem o consumo, diminuem o ritmo biológico e, conseqüentemente, o desempenho piora.
Também foi observado, em pacus (P. mesopotamicus), que o consumo diário de ração foi influenciado pela temperatura, proporcionando índices de ingestão de 2,29 e $2,97 \%$ do peso vivo ao dia, para as temperaturas de 23 e $27^{\circ} \mathrm{C}$, respectivamente. Além disso, os valores de tempo de trânsito gastrintestinal foram influenciados pelas temperaturas, com médias de 36 e 14 horas, para 23 e $27^{\circ} \mathrm{C}$, respectivamente, e a digestão do alimento foi mais lenta a $23^{\circ} \mathrm{C}$ do que a $27^{\circ} \mathrm{C}$, que alcançou menores índices de repleção (Dias-Koberstein et al., 2004). Ao estudar o desempenho de jundiás (Rhamdia quelen), em três temperaturas, 20,23 e $26^{\circ} \mathrm{C}$, Piedras et al. (2004a) observaram que o consumo de ração foi influenciado pela temperatura da água. Porém, o maior consumo foi a $23^{\circ} \mathrm{C}$, mostrando que essa temperatura proporciona melhor conforto térmico nessa espécie.

Quanto ao ganho de peso, foi observado efeito linear $(\mathrm{p}<0,01)$ de acordo com a temperatura (Tabela 3 ). $\mathrm{O}$ aumento do consumo de ração associado à elevação no metabolismo dos peixes, ocasionado pela temperatura, proporcionou maior ganho de peso. As tilápias criadas a $32^{\circ} \mathrm{C}$ apresentaram ganho de peso médio de $45,45 \mathrm{~g}$ a mais do que tilápias submetidas à menor temperatura. Justin et al. (2005) também verificaram que alevinos de tilápias submetidos às temperaturas de $23,26,29$ e $32^{\circ} \mathrm{C}$ alcançaram ganho de peso médio de 6,8,11,2, 14 e 14,4 g, respectivamente. Em tainhas (Mugil platanus), o crescimento em peso e comprimento foi diretamente proporcional à temperatura, com melhor resultado a $30^{\circ} \mathrm{C}$ (Okamoto et al., 2006).

$\mathrm{Na}$ conversão alimentar aparente, foi observado efeito quadrático $(\mathrm{p}<0,01)$ de acordo com os tratamentos, com melhora de 1,79 a 1,00 e aumento da temperatura até $29,15^{\circ} \mathrm{C}$, além da tendência de piorar a partir desse valor (Tabela 3). Baldisseroto (2002) citou que as temperaturas nas quais são verificadas as maiores taxas de consumo de alimento, resultando em crescimento máximo, em geral, não correspondem a melhores

Tabela 2. Temperatura (T), oxigênio dissolvido $\left(\mathrm{O}_{2} \mathrm{D}\right)$ e $\mathrm{pH}$ da água durante o período experimental, em diferentes temperaturas.

\begin{tabular}{lrrrr}
\hline Variáveis físico-químicas & $20^{\circ} \mathrm{C}$ & $24^{\circ} \mathrm{C}$ & $28^{\circ} \mathrm{C}$ & $32^{\circ} \mathrm{C}$ \\
\hline $\mathrm{T}\left({ }^{\circ} \mathrm{C}\right)$ & 20,53 & 24,04 & 27,92 & 31,76 \\
$\mathrm{CV}(\%)$ & 2,27 & 0,65 & 0,64 & 0,63 \\
\hline $\mathrm{O}_{2} \mathrm{D}\left(\mathrm{mg} \mathrm{L}^{-1}\right)$ & 7,20 & 6,80 & 6,60 & 6,50 \\
$\mathrm{CV}(\%)$ & 1,32 & 1,72 & 3,20 & 4,28 \\
\hline $\mathrm{pH}$ & 6,58 & 6,18 & 6,36 & 6,29 \\
$\mathrm{CV}(\%)$ & 1,93 & 3,42 & 3,29 & 2,43 \\
\hline
\end{tabular}


resultados de conversão alimentar. Essas observações foram comprovadas neste trabalho, pois o ganho de peso aumentou linearmente $(\mathrm{p}<0,01)$, enquanto a conversão alimentar melhorou somente até $29,15^{\circ} \mathrm{C}$. Isso não foi observado em bagres-de-canal (Ictalurus punctatus), cujo ganho de peso médio aumentou de 20 para $40,8 \mathrm{~g}$ e a conversão alimentar melhorou de 3,30 para 1,82, respectivamente, ao elevar a temperatura de 20 para $26^{\circ} \mathrm{C}$ (Piedras et al., 2006b).

Em relação à atividade de amilase, houve aumento linear $(\mathrm{p}<0,01)$ à medida que a temperatura da água se elevou (Tabela 3). Para uma diferença de 37,5\% da temperatura mais baixa $\left(20^{\circ} \mathrm{C}\right)$ para a mais alta $\left(32^{\circ} \mathrm{C}\right)$, ocorreu aumento de $16,02 \%$ na atividade de amilase. A temperatura é um fator que interfere na velocidade de reações catalisadas por enzimas. De acordo com Jian et al. (2003), a temperatura é um fator primário que controla as necessidades nutricionais e o esvaziamento gástrico, e com isso, o metabolismo dos peixes.

O resultado deste trabalho também sugere que o maior consumo de ração pelas tilápias, em temperaturas mais elevadas, estimula o pâncreas a produzir maior quantidade de amilase devido ao aumento da concentração de amido no intestino. A presença de alimento no trato digestório resulta em estímulos hormonais (colecistoquinina - CCK), que agem no pâncreas, órgão responsável pela produção de diversas enzimas digestivas (Lovell, 1998). Com o melhor aproveitamento do amido como fonte energética, a proteína foi poupada para a função estrutural, ou seja, desenvolvimento dos tecidos. Isso refletiu no desempenho das tilápias com o aumento da temperatura, o que proporcionou maior ganho de peso e melhor conversão alimentar.
Em duas espécies de bagre (Clarias gariepinus e Heteropneustes fossilis), Usmani \& Jafri (2002) verificaram que a digestibilidade da proteína e de outros nutrientes das rações melhorou com a elevação da temperatura de 18 para $28^{\circ} \mathrm{C}$. Também foi observado por Azevedo et al. (1998) melhora na digestibilidade da dieta de truta-arco-íris (Oncorhynchus mykiss) ao se elevar a temperatura, gradativamente, de 6 para $15^{\circ} \mathrm{C}$. Nessa mesma espécie, Steffens (1987) observou que a atividade de amilase se elevou com o consumo de alimento, com o aumento da temperatura e da salinidade da água.

Outro fator a ser considerado é que a eficiência da catálise enzimática depende do meio. A estrutura e a forma do centro ativo das enzimas podem ser afetadas por agentes capazes de mudar a conformação das proteínas. Por esse motivo é importante o controle de características do meio, como o $\mathrm{pH}$ e a temperatura. $\mathrm{Na}$ temperatura próxima a $0^{\circ} \mathrm{C}$, a atividade das enzimas praticamente é nula, mas aumenta com a elevação gradativa da temperatura (Lehninger et al., 1995). $\mathrm{O}$ aumento da ação enzimática só ocorre enquanto a enzima conservar sua estrutura nativa. Em temperaturas acima de $50^{\circ} \mathrm{C}$, a maioria das enzimas é desnaturada, o que leva a alterações na sua conformação e à perda do poder de ação.

Quanto à atividade específica da amilase, houve redução linear $(\mathrm{p}<0,01)$ com o aumento da temperatura da água (Tabela 3). Esse resultado pode ser explicado pelo fato de os peixes aumentarem o consumo, o que, conseqüentemente, levou ao intestino grandes quantidades de amido e proteína. Tilápias criadas a $32^{\circ} \mathrm{C}$ consumiram 10,27 vezes mais ração do que tilápias criadas a $20^{\circ} \mathrm{C}$. Ao elevar a temperatura, a atividade da amilase aumentou e a atividade específica diminuiu,

Tabela 3. Consumo de ração aparente (CRA), peso inicial (PI), peso final (PF), ganho de peso (GP), conversão alimentar aparente (CAA), atividade de amilase (ATA), atividade específica de amilase (AEA) de tilápia-do-nilo em diferentes da temperaturas.

\begin{tabular}{|c|c|c|c|c|c|c|}
\hline \multirow[t]{2}{*}{ Parâmetros } & \multicolumn{4}{|c|}{ Temperatura $\left({ }^{\circ} \mathrm{C}\right)$} & \multirow[t]{2}{*}{ Ponto de inflexão $\left({ }^{\circ} \mathrm{C}\right)$} & \multirow[t]{2}{*}{$\mathrm{CV}(\%)$} \\
\hline & 20 & 24 & 28 & 32 & & \\
\hline$\overline{\mathrm{CRA}(\mathrm{g})^{(1)}}$ & 41,3 & 150,2 & 302,6 & 424,3 & - & 22,74 \\
\hline PI $(g)$ & 0,831 & 0,832 & 0,840 & 0,838 & - & - \\
\hline $\mathrm{PF}(\mathrm{g})^{(2)}$ & 3,135 & 14,088 & 29,813 & 48,589 & - & 12,11 \\
\hline $\mathrm{GP}(\mathrm{g})^{(3)}$ & 2,30 & 13,26 & 28,97 & 47,75 & - & 12,57 \\
\hline $\mathrm{CAA}\left(\mathrm{g} \mathrm{g}^{-1}\right)^{(4)}$ & 1,79 & 1,15 & 1,10 & 1,04 & 29,15 & 9,07 \\
\hline ATA (UA) $)^{(5)}$ & 30.886 & 32.771 & 34.966 & 36.778 & $\begin{array}{c}- \\
25,13\end{array}$ & 8,74 \\
\hline AEA $\left(\mathrm{UA} \mathrm{mg}^{-1}\right)^{(6)}$ & 186.629 & 171.467 & 126.230 & 90.254 & - & 25,26 \\
\hline
\end{tabular}

${ }^{(1)}$ Efeito linear $(\mathrm{p}<0,01): \hat{\mathrm{Y}}=-616,5210+32,5460 \mathrm{~T} ; \mathrm{R}^{2}=0,99$. (2)Efeito linear $(\mathrm{p}<0,01): \hat{\mathrm{Y}}=-74,3504+3,77571 \mathrm{~T} ; \mathrm{R}^{2}=0,99$. ${ }^{(3)}$ Efeito linear $(\mathrm{p}<0,01): \hat{\mathrm{Y}}=-75,1652+3,77492 \mathrm{~T} ; \mathrm{R}^{2}=0,99$. ${ }^{(4)}$ Efeito quadrático $(\mathrm{p}<0,01): \hat{\mathrm{Y}}=8,99913-0,54887 \mathrm{~T}+0,009413 \mathrm{~T}^{2} ; \mathrm{R}^{2}=0,95$. ${ }^{(5)}$ Efeito linear $(\mathrm{p}<0,01): \hat{\mathrm{Y}}=20931,6+496,873 \mathrm{~T} ; \mathrm{R}^{2}=0,99$. ${ }^{(6)}$ Efeito linear $(\mathrm{p}<0,01): \hat{\mathrm{Y}}=360982-8359,09 \mathrm{~T} ; \mathrm{R}^{2}=0,97$. 
mostrando que o pâncreas não produz amilase em proporções diretas à quantidade de substrato que chega ao duodeno. No entanto, a ação catalítica da amilase aumentou, promovendo eficiência maior na utilização dos nutrientes pelos peixes. Essa redução na produção da enzima é uma medida poupadora de energia e proteína e faz com que esses inssumos sejam utilizados para o ganho de peso.

\section{Conclusões}

1. A temperatura da água influencia o metabolismo das tilápias-do-nilo e afeta o desempenho.

2. A atividade catalítica da amilase em tilápias-do-nilo é influenciada pela temperatura da água.

3. Aos $32^{\circ} \mathrm{C}$, as tilápias apresentam a maior atividade de amilase e a menor atividade específica de amilase.

\section{Referências}

AZEVEDO, P.A.; CHO, C.Y.; LEESON, S.; BUREAU, D.P. Effects of feeding level and water temperature on growth, nutrient and energy utilization and waste outputs of rainbow trout (Oncorhynchus mykiss). Aquatic Living Resources, v.11, p.227-238, 1998.

BALDISSEROTO, B. Fisiologia de peixes aplicada à piscicultura. Santa Maria: UFSM, 2002. 212p.

BOYD, C.E. Water quality management for pond fish culture: developments in aquaculture and fisheries science. Amsterdam: Elsevier Science Publishers, 1982. 318p.

CAHU, C.L.; ZAMBONINO-INFANTE, J.L. Early weaning of sea bass (Dicentrarchus labrax) larvae with a compound diet: effect on digestive enzymes. Compendium of Biochemistry and Physiology, v.109A, p.213-222, 1994.

CARAWAY, W.T. A stable starch substrate for the determination of amylase in serum and other body fluids. American Journal of Clinical Pathology, v.32, p.97-99, 1959.

CORREA, C.F. Estudo dos padrões de digestão enzimática e perfil metabólico em tambaqui, Colossoma macropomum (Cuvier, 1818) alimentado com diferentes teores de proteína e carboidratos em regime de confinamento. 2002. 115p. Tese (Doutorado) - Universidade Federal de São Carlos, São Carlos.

CORRÊA, C.F.; BIDINOTTO, P.M.; MORAES, G. Comparison of the amilohydrolitic activity in the gut of the neotropical teleost species Pacu Piaractus mesopotamicus and Tambacu hybrid (Colossoma macropomum Tambaqui x P. mesopoptamicus Pacu) submitted to different contents of soluble carbohydrate. In: INTERNATIONAL CONGRESS ON BIOLOGY OF FISH, 3., 1998, Baltimore. Proceedings. Baltimore: [s.n.], 1998. p.87-99.

DIAS-KOBERSTEIN, T.C.R.; CARNEIRO, D.J.; URBINATI, E.C. Comportamento alimentar de alevinos de pacu (Piaractus mesopotamicus, Holmberg, 1887) por meio das observações do tempo de retorno do apetite e do tempo de saciação dos peixes em duas temperaturas de cultivo. Acta Scientiarum, v.26, p.339344, 2004.

FURUYA, W.M.; HAYASHI, C.; FURUYA, V.R.B.; BOTARO, B.; SILVA, L.C.; NEVES, P.R. Exigências de metionina + cistina total e digestível para alevinos revertidos de tilápia do Nilo, Oreochromis niloticus (L.), baseadas no conceito de proteína ideal. Acta Scientiarum, v.23, p.885-889, 2001a.

FURUYA, W.M.; SANTOS, V.G.; SILVA, L.C.R.; SILVA, T.C.; FURUYA, V.R.B.; SAKAGUTI, E.S. Exigências de lisina digestível para juvenis de tilápia-do-nilo. Revista Brasileira de Zootecnia, v.35, p.937-942, 2006 (supl.).

GLASS, H.J.; MCDONALD, N.L.; MORAN, R.M.; STARK, J.R. Digestion of protein in different marine species. Comparative Biochemistry and Physiology, v.91B, p.607-611, 1989.

JIAN, C.Y.; CHENG, S.Y.; CHEN, J.C. Temperature and salinity tolerances of yellowfin sea bream, Acanthopagrus latus, at different salinity and temperature levels. Aquaculture Research, v.34, p.175-185, 2003.

JIN, L.Z.; HO, Y.W.; ABDULLAH, N.; JALALUDIN, S. Growth performance, intestinal microbial populations, and serum cholesterol of broilers fed diets containing Lactobacillus cultures. Poultry Science, v.77, p.1259-1265, 1998.

JUSTI, K.C.; PADRE, R.G.; HAYASHI, C.; SOARES, C.M.; VISENTAINER, J.V.; SOUZA, N.E.; MATSUSHITA, M. Efeito da temperatura da água sobre desempenho e perfil de ácidos graxos de tilápia do Nilo (Oreochromis niloticus). Acta Scientiarum, v.24, p.529-534, 2005.

KUBITZA, F. Tilápia: tecnologia e planejamento na produção comercial. Jundiaí: Fernando Kubitza, 2000. 289p.

LEHNINGER, A.L.; NELSON, D.L.; COX, M.M. Princípios de bioquímica. 2.ed. São Paulo: Sarvier, 1995. 841p.

LOVELL, R.T. Nutrition and feeding of fish. Boston: Kluwer Academic Publishing, 1998. 267p.

MORAES, G.; BIDINOTTO, P.M. Induced changes in the amylohydrolitic profile of the gut of Piaractus mesopotamicus (Holmberg, 1885) fed different levels of soluble carbohydrates; its correlation with metabolic aspects. Revista de Ictiologia, v.8, p.47-51, 2000.

NATIONAL RESEARCH COUNCIL. Nutrient requirements of warm water, fishes and shellfishes: nutrient requirements of domestic's animals. Washington: National Academic Press, 1993. 114p.

OKAMOTO, M.H.; SAMPAIO, L.A.; MAÇADA, A.P. Efeito da temperatura sobre o crescimento e a sobrevivência de juvenis da tainha Mugil platanus Günther, 1880. Revista Atlântica, v.28, p.61-66, 2006.

PERAGÓN, J.; BARROSO, J.B.; GARCIA-SALGUEIRO, L.; HIGUERA, M.; LUPÍAÑEZ, J.A. Dietary protein effects on growth and fractional protein synthesis and degradation rates in liver and white muscle of rainbow trout (Oncorhynchus mykiss). Aquaculture, v.124, p.35-46, 1994.

PIEDRAS, S.R.N.; MORAES, P.R.R.; POUEY, J.L.O.F. Crescimento de juvenis de jundiá (Rhamdia quelen), de acordo com a temperatura da água. Boletim do Instituto de Pesca, v.30, p.177-182, 2004a. 
PIEDRAS, S.R.N.; MORAES, P.R.R.; POUEY, J.L.O.F. Desempenho de juvenis de catfish (Ictalurus punctatus) em diferentes temperaturas. Revista Brasileira de Agrociência, v.12, p.367-370, 2006b.

PIPER, R.G.; McELWAIN, I.B.; ORME, L.E. Fish Hatchery Management. Washington: U.S. Department of Interior, 1982, 517p.

PURCHASE, C.F.; BROWN, J.A. Stock-specific changes in growth rates, food conversion efficiencies, and energy allocation in response to temperature change in juvenile Atlantic cod. Journal of Fish Biology, v.58, p.36-52, 2001.

RIBEIRO, F.B.; LANNA, E.A.T.; BOMFIM, M.A.D.; DONZELE, J.L.; FREITAS, A.S.; SOUSA, M.P.; QUADROS, M. Níveis de fósforo total em dietas para alevinos de tilápia-do-nilo. Revista Brasileira de Zootecnia, v.35, p.1588-1593, 2006.

ROSTAGNO, R.S.; ALBINO, L.F.T.; DONZELE, J.L.; GOMES, P.C.; OLIVEIRA, R.F.; FERREIRA, A.S.; BARRETO, S.L.T. Tabelas brasileiras para aves e suínos: composição de alimentos e exigências nutricionais. 2.ed. Viçosa: Universidade Federal de Viçosa, 2005. 186p.

SABAPATHY, U.; TEO, L.H. A quantitative study of some digestive enzymes in the rabbitfish, Siganus canaliculatus and the sea bass, Lates calcarifer. Journal of Fish Biology, v.42, p.595-602, 1993.

SEIXAS FILHO, J.T.; OLIVEIRA, M.G.A.; DONZELE, J.L.; GOMIDE, A.T.M.; MENIN, E. Atividade de amilase em quimo de três espécies tropicais de peixes teleostei de água doce. Revista da Sociedade Brasileira de Zootecnia, v.28, p.907-913, 1999.

SHIAU, S.Y.; CHUANG J.C. Utilization of disaccharides by juvenile tilapia Oreochromis niloticus x Oreochromis aureus. Aquaculture, v.133, p.249-256, 1995.

UNIVERSIDADE FEDERAL DE VIÇOSA. SAEG: sistemas para análises estatísticas e genéticas: versão 9.0. Viçosa: Fundação Arthur Bernardes, 2004.

STEFFENS, W. Principios fundamentales de la alimentacíon de los peces. Zaragoza: Acribia, 1987. 280p.

USMANI, N.; JAFRI, A.K. Effect of fish size and temperature on the utilization of different protein sources in two catfish species. Aquaculture Research, v.33, p.959-967, 2002.

WARBURG, O.; CHRISTIN, W. Isohering und kristallisation des gõrungs ferments enolase. Biochemistry Zoology, v.310, p.384-421, 1941.

Recebido em 8 de maio de 2007 e aprovado em 29 de outubro de 2007 